\title{
OPEN Author Correction: Weight Bearing Activities change the Pivot Position after Total Knee Arthroplasty
}

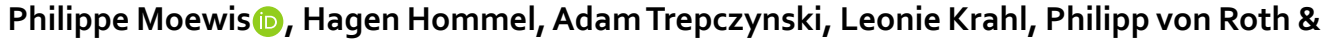 Georg N. Duda}

Correction to: Scientific Reports https://doi.org/10.1038/s41598-019-45694-y, published online 24 June 2019

The Acknowledgements section in this Article is incomplete.

“This work was supported by Implantcast GmbH, the European Regional Development Fund (EFRE, 16409608, OrthoLoadLab), the Federal Ministry of Education and Research (BMBF, OVERLOAD-PrevOP, 01EC1408A), the German Research Foundation (DFG, TR 1657/1-1) and the OrthoLoad Club. We also acknowledge support from the German Research Foundation (DFG) and the Open Access Publication Funds of Charité Universitätsmedizin Berlin.”

should read:

“This work was supported by Implantcast GmbH, the European Regional Development Fund (EFRE, 16409608, OrthoLoadLab), the Federal Ministry of Education and Research (BMBF, OVERLOAD-PrevOP, 01EC1408A), the German Research Foundation (DFG, TR 1657/1-1) and the OrthoLoad Club. We also acknowledge support from the German Research Foundation (DFG) and the Open Access Publication Funds of Charité - Universitätsmedizin Berlin. Additionally, we would like to thank Dr. Sabine Schmitt and her team at the Krankenhaus Martha-Maria Halle Dölau for their support during patient selection, recruitment and general organization of the study."

\begin{abstract}
(c) (i) Open Access This article is licensed under a Creative Commons Attribution 4.0 International License, which permits use, sharing, adaptation, distribution and reproduction in any medium or format, as long as you give appropriate credit to the original author(s) and the source, provide a link to the Creative Commons license, and indicate if changes were made. The images or other third party material in this article are included in the article's Creative Commons license, unless indicated otherwise in a credit line to the material. If material is not included in the article's Creative Commons license and your intended use is not permitted by statutory regulation or exceeds the permitted use, you will need to obtain permission directly from the copyright holder. To view a copy of this license, visit http://creativecommons.org/licenses/by/4.0/.
\end{abstract}

(C) The Author(s) 2020 